\title{
DETECTION PROBABILITY OF GYRFALCONS AND OTHER CLIFF-NESTING RAPTORS DURING AERIAL SURVEYS IN ALASKA
}

\author{
Travis L. Booms ${ }^{1,2}$, Philip F. SchempF ${ }^{3}$, Brian J. McCaffery 4 , \\ Mark S. LINDBERG ${ }^{1}$, AND MARK R. FulleR ${ }^{5}$
}
${ }^{1}$ University of Alaska Fairbanks, Biology and Wildlife Department and Institute of Arctic Biology, 211 Irving 1, Fairbanks, AK 99775, USA

${ }^{2}$ Current address: Alaska Department of Fish and Game, Wildlife Diversity Program, 1300 College Road, Fairbanks, AK 99701,USA. E-mail: travis.booms@alaska.gov

${ }^{3}$ US Fish and Wildlife Service, Migratory Bird Management - Raptors, 3000 Vintage Boulevard Suite 240, Juneau, AK 99801, USA

${ }^{4}$ US Fish and Wildlife Service, Yukon Delta National Wildlife Refuge, P.O. Box 346, Bethel, AK 99559, USA

\section{${ }^{5}$ U.S. Geological Survey, Forest and Rangeland Ecosystem Science Center, and Boise State University Raptor Research Center, 970 Lusk Street, Boise, ID 83706, USA}

\begin{abstract}
EXTENDED ABSTRACT.-Assessing the status of Gyrfalcons (Falco rusticolus) and other cliffnesting raptors as the Arctic climate changes often requires aerial surveys of their breeding habitats. Because traditional, count-based surveys that do not adjust for differing detection probabilities can provide faulty inference about population status (Link and Sauer 1998, Thompson 2002), it will be important to incorporate measures of detection probability into survey methods whenever possible.
\end{abstract}

To evaluate the feasibility of this, we conducted repeated aerial surveys for breeding cliff-nesting raptors on the Yukon Delta National Wildlife Refuge (YDNWR) in western Alaska to estimate detection probabilities of Gyrfalcons, Golden Eagles (Aquila chrysaetos), Rough-legged Hawks (Buteo lagopus), and also Common Ravens (Corvus corax). Using the program PRESENCE, we modeled detection histories of each species based on single species occupancy modeling following MacKenzie et al. (2002, 2006). We used different observers during four helicopter replicate surveys in the Kilbuck Mountains and five fixed-wing replicate surveys in the Ingakslugwat Hills (hereafter called Volcanoes) near Bethel, Alaska.

We used the following terms and definitions throughout: Survey Site: site of a nest used previously by a raptor and marked with a GPS-obtained latitude and longitude accurate to within $20 \mathrm{~m}$. All GPS locations were obtained in prior years from a helicopter hovering approximately $10-20 \mathrm{~m}$ from a nest. The site was considered occupied if a bird or an egg was detected within approximately $500 \mathrm{~m}$ of the nest and this area served as our sampling unit. When multiple historical nests were located on a single cliff, we used only 
one GPS location to locate the survey site. Detection probability $(p)$ : the probability of a species being detected at a site given the site is occupied. Occupancy $(\psi)$ : the probability that the species of interest is present at a site during the survey period. A site was considered occupied if the species was detected there during any of the surveys; confirming breeding status was not necessary for us to consider a site occupied.

Here we show that during helicopter surveys, Gyrfalcons had the highest detection probability estimate ( $\hat{p} ; \hat{p}=0.79$; SE 0.05$)$, followed by Golden Eagles ( $\hat{p}=0.68$; SE 0.05), Common Ravens ( $\hat{p}=0.45$; SE 0.17), and Rough-legged Hawks ( $\hat{p}=0.10$; SE 0.11) (Table 1). Detection probabilities from fixed-wing aircraft in the Volcanoes were similar to those from the helicopter in the Kilbuck Mountains for Gyrfal- cons and Golden Eagles, but were higher for Common Ravens ( $\hat{p}=0.85$; SE 0.06) and Rough-legged Hawks ( $\hat{p}=0.42$; SE 0.07). Fixed-wing aircraft provided detection probability estimates and SEs in the Volcanoes similar to or better than those from helicopter surveys in the Kilbucks and should be considered for future cliff-nesting raptor surveys where safe, low-altitude flight is possible.

Overall, detection probability varied by observer experience and in some cases, by study area/aircraft type. These results demonstrate that estimating and accounting for detection probability during cliff-nesting raptor surveys is possible, though doing so may require additional effort or shifting priorities in survey protocols. Received 2 March 2011, accepted 9 May 2011.

Booms, T. L, P. F. Schempf, B. J. McCAFFERY, M. S. LindBerg, AND M. R. FulLeR. 2011. Detection probability of Gyrfalcons and other cliff-nesting raptors during aerial surveys in Alaska. Extended abstract, pages 259-262 in R. T. Watson, T. J. Cade, M. Fuller, G. Hunt, and E. Potapov (Eds.). Gyrfalcons and Ptarmigan in a Changing World, Volume I. The Peregrine Fund, Boise, Idaho, USA. http://dx.doi.org/10.4080/gpcw.2011.0124

Key words: Alaska, aerial surveys, detection probability, mountains, Gyrfalcons, Golden Eagles, Rough-legged Hawks, Common Ravens.

This paper was originally published in full as: Booms, T. L, P. F. SCHEMPF, B. J. MCCAFFERY, M. S. LiNDBERG, AND M. R. FULlER. 2010. Detection probability of cliff-nesting raptors during helicopter and fixed-wing aircraft surveys in Western Alaska. Journal of Raptor Research 44:175187. 


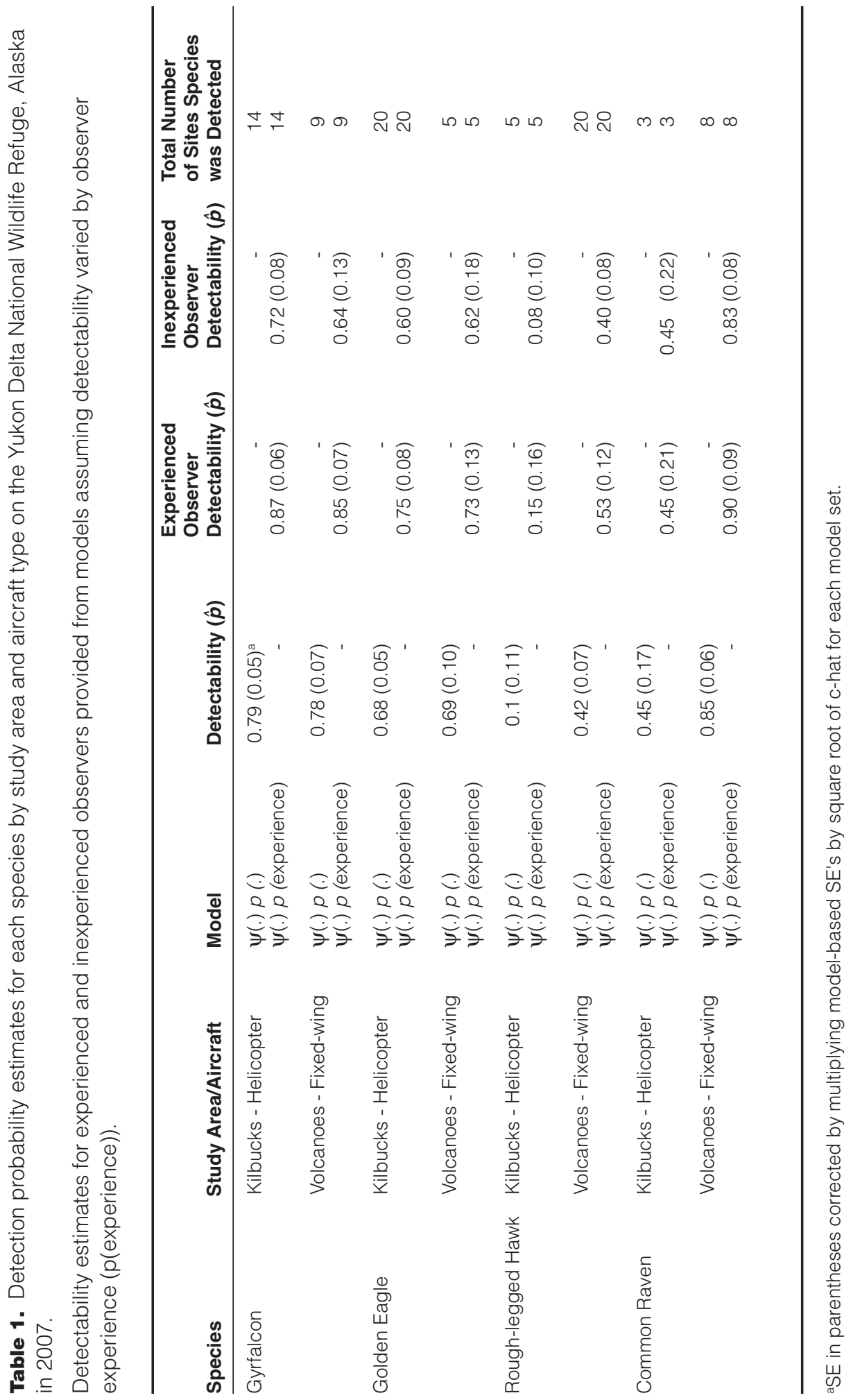




\section{ACKNOWLEDGMENTS}

This work was funded by the US Fish and Wildlife Service Office of Migratory Birds Raptor Management Office. TLB was supported by a US Environmental Protection Agency (EPA) Science to Achieve Results Graduate Fellowship, a University of Alaska Fairbanks Thesis Completion Fellowship, and the Alaska Department of Fish and Game Wildlife Diversity Program while conducting portions of this work. The EPA has not officially endorsed this publication and the views expressed herein may not reflect the views of the EPA. We thank F. Broerman and J. Spice for conducting replicate surveys and for valuable input. YDNWR provided essential logistical support. We thank S. Hermens of Hermens Helicopters and $\mathrm{H}$. Twitchell of YDNWR for piloting survey replicates and providing constructive feedback and insights. Any use of trade, product, or firm names is for descriptive purposes only and does not imply endorsement by the US Government. Although PFS and BJM are employees of the US Fish and Wildlife Service, the findings and conclusions in this article are those of the authors and do not necessarily represent the views of the Service.

\section{Literature Cited}

LiNK, W. A., AND J. R. SAUER. 1998. Estimating population change from count data: Application to the North American breeding bird survey. Ecological Applications 8:258-268.

MacKenzie, D. L., J. D. Nichols, G. B. LaChman, S. Droege, J. A. Royle, and C. A. LANGTIMM. 2002. Estimating site occupancy rates when detection probabilities are less than one. Ecology 83:2248-2255.

MacKenzie, D. L., J. D. Nichols, J. A. Royle, K. H. Pollock, L. L. Bailey, And J. E. Hines. 2006. Occupancy Estimation and Modeling. Academic Press, New York, USA.

ThOMPSON, W. L. 2002. Towards reliable bird surveys: Accounting for individuals present but not detected. Auk 119:18-25. 